\title{
Insulin Glargine versus Neutral Protamine Hagedorn Insulin in Young and Preschool Children with Type 1 Diabetes Mellitus
}

\author{
Khadiga Eltonbary*1, Manal Abd Alaziz ${ }^{2}$, Assad Abolela ${ }^{1}$, Eman M Sherif ${ }^{1}$ \\ Departments of ${ }^{1}$ Paediatrics and ${ }^{2}$ Clinical Pathology, Faculty of Medicine, Ain Shams University, Cairo, Egypt. \\ *Corresponding author: Khadiga Yehia Eltonbary, Phone: 00201010477244, Email: khadigadoc@yahoo.com
}

\begin{abstract}
Background: Diabetic patients need to maintain tight glycemic control to avoid long term complications. Children need to achieve tight control without the risk of hypoglycemic excursions.

Objective: To assess the safety and efficacy of insulin glargine as a basal insulin in type 1 diabetic children aged 3 to 8 years old in comparison to neutral protamine Hagedorn (NPH) insulin as regards the key parameters of diabetes management and low-grade inflammation.

Patients and Methods: Fifty children aged 3-8 years old with type 1 diabetes mellitus following in pediatric diabetes clinic, Ain Shams University Hospital were enrolled in this study. They were randomized into two groups, group A: shifted from NPH insulin to basal-bolus regimen using insulin glargine once a day and group B: kept on using NPH insulin two to three times a day. Both used regular insulin or rapid acting analogues at mealtime.

Results: At six months, weight gain was significantly higher among group B patients $0.6 \mathrm{~kg}( \pm 0.14 \mathrm{SD}) \mathrm{vs} 0.38 \mathrm{~kg}$, mean fasting blood sugar was lower in group A, 109.1 $( \pm 17) \mathrm{mg} / \mathrm{dl}$ versus $125.3( \pm 20) \mathrm{mg} / \mathrm{dl}$ in group B. HbA1C showed significant improvement in both groups with tight control, however group A was better with a mean of $6.7( \pm 0.5) \%$ versus 7.4( \pm 0.7$)$ and still with significantly less hypoglycemic excursions. Hs-CRP as a marker of inflammation showed significant drop with better overall control independent of the basal insulin used.

Conclusion: Insulin glargine as once daily basal insulin is safe in achieving good glycemic control in young and preschool children with less hypoglycemic excursions.
\end{abstract}

Keywords: Insulin Glargine, Neutral Protamine Hagedorn insulin, Type 1 diabetes mellitus.

\section{INTRODUCTION}

Diabetic patients should maintain tight glycemic control, with a hemoglobin A1c (HbA1C) concentration of 7.0 percent or less, to lower the risk of long-term consequences such as cardiovascular mortality, retinopathy, and nephropathy ${ }^{(1)}$.

NPH (Neutral Protamine Hagedorn) insulin is an insoluble intermediate-acting insulin. $\mathrm{N}$ is for neutral, $\mathrm{P}$ for protamine (a protein), and $\mathrm{H}$ stands for Hans Hagedorn, the scientist who created it. Insulin glargine is an insulin analogue with a lower solubility at physiological $\mathrm{pH}$ than natural insulin, allowing for a longer absorption time after subcutaneous injection and a consistent 24-hour basal insulin supply ${ }^{(2)}$.

A normal-growing child with type 1 diabetes needs about 0.7-1 IU of insulin per $\mathrm{kg}$ of body weight per day after the end of the remission phase. Approximately $30-40 \%$ of this is to be administered as basal insulin ${ }^{(3)}$.

Before introduction of long-acting analogues and to initiate multiple daily injections, the use of NPH insulin was recommended to tailor the dose to the circadian variation of insulin requirement. The basal dose of intermediate-action NPH insulin is frequently divided into two to three injection intervals to match the basal insulin need at different times ${ }^{(4)}$. For children younger than eight years, especially those younger than six, it is hard to detect hypoglycemia, their activity is unpredictable, and they have many dietary discrepancies, and so it is a serious concern of their families. With multiple daily injections and NPH, good glycemic control can be achieved however severe hypoglycemia is still a risk ${ }^{(5)}$.

Studies have shown that administering insulin glargine instead of NPH improves glycemic control and reduces hypoglycemic episodes, particularly nocturnal episodes, which are prevalent in children ${ }^{(6)}$. The highly sensitive C-reactive protein (Hs-CRP) is a marker of low-grade inflammatory state that characterizes the early stages of atherosclerosis. Inflammatory markers in diabetes type 2 and metabolic syndrome in adults are well studied, but less is known about the inflammatory process in diabetes type 1, particularly in children ${ }^{(7)}$.

The purpose of this study was to assess the safety and efficacy of insulin glargine as a basal insulin therapy in type 1 diabetic children aged 3 to 8 years old in comparison to NPH insulin as regards the impact on key parameters of diabetes management and low grade inflammation.

\section{PATIENTS AND METHODS}

The study was performed at the Pediatric Diabetes Clinic, Ain Shams University Hospital. Fifty children aged 3-8 years old with type 1 diabetes mellitus (DM) were randomly enrolled in this study.

They were randomized into two groups: Group A: Shifted to basal-bolus regimen using insulin glargine once a day and regular insulin or rapid acting analogues 
at mealtime, and Group B: Kept on basal-bolus regimen using NPH insulin two to three times a day and regular insulin or rapid acting analogues at mealtime.

\section{Inclusion criteria}

Type 1 diabetic children, age between three and eight years, complaining parents and patients ready to do self-monitoring of blood glucose (SMBG) at least four to six times daily, and did not receive glargine insulin before.

\section{Exclusion criteria}

Patients experiencing the honeymoon period were excluded from the study, patients with significant comorbidity, and patients refusing frequent SMBG.

\section{All patients were regularly assessed for six months:}

Clinically for diabetes control, frequency of severe hypoglycemic attacks, which included nocturnal hypoglycemia, insulin dosage in units $/ \mathrm{kg} /$ day and occurrence of diabetic ketoacidosis.

Laboratory work up included mainly HbA1c assessed by high performance liquid chromatography at 3 and 6 months, SMBG using Bionime glucometer at least 4-6 times a day and once during sleep and highly sensitive C-reactive protein baseline and at the end of the study using latex augmented method.

\section{Ethical consent:}

An approval of the study was obtained from Ain Shams University Academic and Ethical Committee. Every caregiver of each patient signed an informed written consent for acceptance of sharing in the study. This work was carried out in accordance with The Code of Ethics of the World Medical Association (Declaration of Helsinki) for studies involving humans.

\section{Statistical analysis}

The collected data were coded, processed and analyzed using the SPSS (Statistical Package for the Social Sciences) version 20 for Windows ${ }^{\circledR}$ (IBM SPSS Inc, Chicago, IL, USA). Description of quantitative variables was as mean, standard deviation (SD) and range, while description of qualitative variables was as number and percentage. Chi-square test was used to compare qualitative variables and Fisher exact test was used instead of chi-square when one expected cell was less than or equal 5. Unpaired t-test was used to compare two groups as regard parametric variables. $\mathrm{P}<0.05$ was considered significant.

\section{RESULTS}

Group A included nine males and 16 females, while group B had 15 males and 10 females. The mean age was 6.1 $( \pm 2 \mathrm{SD})$ years in group A and 5.4 years $( \pm 1.6$ $\mathrm{SD})$ in group B.

There was no significant difference between both groups as regards the initial mean weight, 20.2( $\pm 2 \mathrm{SD}$ ) in group A versus 22.3( $\pm 2 \mathrm{SD})$ in group B; however, weight gain was significantly higher among group $\mathrm{B}$ patients $0.6 \mathrm{~kg}( \pm 0.14 \mathrm{SD})$ vs $0.38 \mathrm{~kg}( \pm 0.13 \mathrm{SD})$ at the end of the study period. $(\mathrm{p}<0.05)$.

Although the total daily dose (TDD) was lower as expected in glargine group, there was no significant difference between both groups as regards the dose. Some patients using insulin glargine reported local irritation at the time of injection however local complications were more among group B patients.

Caregivers reported improved allover control, however, fasting blood sugar was significantly better among glargine group or group A especially when compared to pre study levels. Improvement in postprandial levels was noticed still among group A patients, however this cannot be primarily attributed to basal insulin. Table 1 shows different blood sugar readings among both groups.

Table (1): Comparison between both groups as regard fasting and postprandial sugar

\begin{tabular}{|l|c|c|c|}
\hline Variables & $\begin{array}{c}\text { Group A } \\
\mathrm{N}=25\end{array}$ & $\begin{array}{c}\text { Group B } \\
\mathrm{N}=25\end{array}$ & P \\
\hline $\begin{array}{l}\text { FBS before } \\
\text { study (mg/dl) }\end{array}$ & $157.8 \pm 17$ & $152 \pm 17$ & $>0.05$ \\
\hline $\begin{array}{l}\text { FBS after } \\
\text { study (mg/dl) }\end{array}$ & $109.1 \pm 17$ & $125.3 \pm 20$ & $<0.004$ \\
\hline $\begin{array}{l}\text { 2hrs post- } \\
\text { prandial } \\
\text { (breakfast) } \\
\text { (mg/dl) }\end{array}$ & $132 \pm 16.8$ & $146.2 \pm 25$ & $<0.03$ \\
\hline $\begin{array}{l}\text { Pre-lunch } \\
\text { (mg/dl) }\end{array}$ & $149.1 \pm 23$ & $160.4 \pm 30$ & $>0.05$ \\
\hline $\begin{array}{l}\text { 2hrs } \\
\text { postprandial } \\
\text { (lunch) } \\
\text { (mg/dl) }\end{array}$ & $163.8 \pm 26$ & $172 \pm 24.9$ & $>0.05$ \\
\hline $\begin{array}{l}\text { Pre-dinner } \\
\text { (mg/dl) }\end{array}$ & $177 \pm 27$ & $178 \pm 28$ & $>0.05$ \\
\hline $\begin{array}{l}\text { 2hrs } \\
\text { postprandial } \\
\text { (dinner) } \\
\text { (mg/dl) }\end{array}$ & $192 \pm 16.5$ & $211 \pm 29$ & $<0.01$ \\
\hline
\end{tabular}

FBS: fasting blood sugar

With better control, still hypoglycemic events were significantly less reported, especially the mild to moderate attacks among patients in glargine group. Table 2 shows different reports of hypoglycemic events and reported ketoacidosis among patients of both groups.

Table (2): Comparison between both groups as regard hypoglycemic attacks and reported ketoacidosis 


\begin{tabular}{|c|c|c|c|}
\hline & $\begin{array}{c}\text { Group } \\
\mathbf{A} \\
\mathrm{N}=25\end{array}$ & $\begin{array}{c}\text { Group } \\
\text { B } \\
\mathrm{N}=25 \\
\end{array}$ & $\mathbf{P}$ \\
\hline $\begin{array}{l}\text { Nocturnal } \\
\text { hypoglycemia }\end{array}$ & $6(24 \%)$ & $9(36 \%)$ & $>0.05$ \\
\hline $\begin{array}{l}\text { Severe } \\
\text { hypoglycemia / } \\
\text { month } \\
\text { No } \\
1 \\
2 \\
3 \\
4\end{array}$ & $\begin{array}{c}15(60 \%) \\
9(36 \%) \\
1(4 \%) \\
0(00 \%) \\
0\end{array}$ & $\begin{array}{c}10(40 \%) \\
11(44 \%) \\
2(8 \%) \\
2(8 \%) \\
0\end{array}$ & $>0.05$ \\
\hline $\begin{array}{l}\text { Mild to moderate } \\
\text { /month } \\
\text { No } \\
1 \\
2 \\
3 \\
4 \\
\end{array}$ & $\begin{array}{c}3(12 \%) \\
11(44 \%) \\
5(20 \%) \\
4(16 \%) \\
2(8 \%)\end{array}$ & $\begin{array}{c}1(4 \%) \\
2(8 \%) \\
5(20 \%) \\
11(44 \%) \\
6(24 \%)\end{array}$ & $<0.001$ \\
\hline $\begin{array}{l}\text { Diabetic } \\
\text { ketoacidosis } \\
\text { No } \\
1 \\
2\end{array}$ & $\begin{array}{c}19(76 \%) \\
6(24 \%) \\
0\end{array}$ & $\begin{array}{c}20(80 \%) \\
4(16 \%) \\
1(4 \%)\end{array}$ & $>0.05$ \\
\hline
\end{tabular}

As regards, $\mathrm{HbA1C}$, there was no significant difference between both groups at the start of the study but patients in both groups showed significant improvement in their blood sugar control as reflected by improvement in $\mathrm{HbA} 1 \mathrm{C}$ but when in comparison, glargine group had significant improvement at both 3 and 6 months. Hs-CRP as marker of inflammation was significantly better at the end of the study in each group separately but there was no significant difference between both study groups (Table 3 ).

Table (3): Difference between both groups in both $\mathrm{HbA} 1 \mathrm{C}$ and Hs-CRP initially, during and at the end of the study.

\begin{tabular}{|l|c|c|c|}
\hline \multicolumn{1}{|c|}{ Variables } & $\begin{array}{c}\text { Group A } \\
\mathrm{N}=25\end{array}$ & $\begin{array}{c}\text { Group B } \\
\mathrm{N}=25\end{array}$ & P \\
\hline $\begin{array}{l}\text { HbA1C\% } \\
\text { before }\end{array}$ & $8.1 \pm 0.8$ & $8.6 \pm 1.2$ & $>0.05$ \\
\hline $\begin{array}{l}\text { HbA1C\% } \\
\text { after 3 months }\end{array}$ & $7.3 \pm 0.5$ & $7.8 \pm 0.9$ & $<0.05$ \\
\hline $\begin{array}{l}\text { HBA1C\% } \\
\text { after 6months }\end{array}$ & $6.7 \pm 0.5$ & $7.4 \pm 0.7$ & $<0.001$ \\
\hline $\begin{array}{l}\text { Hs-CRP } \\
\text { (mg/l) initially }\end{array}$ & $1.4 \pm 0.06$ & $1.8 \pm 0.09$ & $>0.05$ \\
\hline $\begin{array}{l}\text { Hs-CRP } \\
\text { (mg/l), end of } \\
\text { study }\end{array}$ & $0.69 \pm 0.02$ & $0.90 \pm 0.02$ & $>0.05$ \\
\hline
\end{tabular}

Insulin glargine is a long-acting human insulin analogue that is routinely used in the treatment of type 1 diabetes mellitus, accounting for $40 \%$ to half of the daily insulin dose. In April 2000, glargine was approved for use in patients with type 1 age 6 or older by the US Food and Drug Administration ${ }^{(8,9)}$. It is usually administered once daily in comparison to two-three times daily for NPH insulin. In the current study, patients on insulin glargine showed significantly less weight gain than patients on NPH insulin given twice or three times daily.

This is in agreement with a meta-analysis by

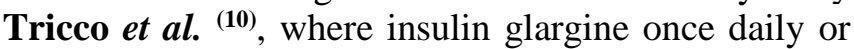
detemir once or twice daily were associated with significantly less weight gain than NPH. On the contrary, an Egyptian study ${ }^{(11)}$, involving adolescents not preschool and younger children reported significant increase in body mass index on insulin glargine when compared to NPH. This difference could be related not only to insulin type but to the adolescent age group, also the increase in body mass index in some reports could be attributed to the improved metabolic control and insulin glargine's 6-fold stronger efficacy at the insulinlike growth factor-1(IGF-1) receptor than conventional human insulin ${ }^{(\mathbf{1 2})}$.

Although a $20 \%$ reduction in dose is usually done before shifting from NPH to glargine, however at the end of the study there was no significant difference in totally daily dose between both groups.

Both groups showed improved fasting blood sugar at 6 months compared to baseline, however as agreed by multiple studies ${ }^{(2,13,14)}$ improvement was significantly noticed among the patients receiving glargine. With improvement in overall control, both groups showed improvement in $\mathrm{HbA} 1 \mathrm{C}$ but the glargine group also showed significant improvement over the $\mathrm{NPH}$ group. In comparison, a lot of studies reported improvement in fasting blood sugar but insignificant difference in $\mathrm{HbA1C}{ }^{(\mathbf{1 1}, 15)}$.

One of the significant complications of insulin therapy in type 1 diabetic children is hypoglycemia especially in young and preschool children. In the current study there was significant decline in hypoglycemic attacks, especially the mild to moderate hypoglycemic events. This decline was appreciated by families as it alleviates one of the main family concerns in diabetes management. This is in agreement with several reports ${ }^{(\mathbf{1 6}, \mathbf{1 7})}$.

Hs-CRP is considered one of the best inflammation markers in clinical practice ${ }^{(18)}$ but it has been poorly studied in children with type 1 diabetes, however a recent report by Pérez-Segura et al. ${ }^{(19)}$ observed higher hs-CRP levels in children with type 1 diabetes than in controls with comparable body mass index, reflecting a basal inflammatory state that may enhance cardiovascular risk. In the current study, with close follow up there was significant decline in hs-CRP levels among both groups and this may point to a 
conclusion that no insulin is superior as long glycemic control is attained.

\section{CONCLUSION}

Basal bolus regimen using insulin glargine once daily is effective in achieving glycemic control. Less hypoglycemic episodes are observed with insulin glargine and still $\mathrm{HbA1C}$ levels showed improvement. Controlling blood sugar by glargine or NPH as basal insulins, could alleviate and improve baseline line inflammation detected in patients with diabetes.

\section{REFERENCES}

1. Singh S, Ahmad F, Lal A et al. (2009): Efficacy and safety of insulin analogues for the management of diabetes mellitus: a meta-analysis. CMAJ., 180(4):38597.

2. Liu M, Zhou Z, Yan J et al. (2016): A randomised, open-labelstudy of insulin glargine or neutral protamine Hagedorn insulin in Chinese paediatric patients with type 1 diabetes mellitus. BMC Endocr Disord., 16(1):111.

3. Danne T, Phillip M, Buckingham B et al. (2018): ISPAD Clinical Practice Consensus Guidelines 2018: Insulin treatment in children and adolescents with diabetes. Pediatr Diabetes, 19:115-35.

4. Biester T, Kordonouri O, Danne $T$ (2018): Pharmacotherapy of type 1 diabetes in children and adolescents: more than insulin? Ther Adv Endocrinol Metab., 9(5):157-66.

5. Dixon B, Peter Chase H, Burdick J et al. (2005): Use of insulin glargine in children under age 6 with type 1 diabetes. Pediatr Diabetes, 6(3):150-4.

6. Rostami P, Setoodeh A, Rabbani A et al. (2014): A randomized clinical trial of insulin glargine and aspart, compared to NPH and regular insulin in children with Type 1 diabetes mellitus. Iran J Pediatr., 24(2):173-178.

7. Glowińska-Olszewska B, Urban M, Peczyńska J et al. (2007): hsCRP protein in children and adolescents with diabetes type 1. Pediatr Endocrinol Diabetes Metab., 13(2):79-84.

8. Chalk B, Crane J, Yenokyan G et al. (2019): Insulin glargine dose and weight changes in underweight, normal weight, and overweight children newly diagnosed with type 1 diabetes mellitus. Pharmacother J Hum Pharmacol Drug Ther., 39(7):741-8.
9. Tan C, Wilson D, Buckingham B (2004): Initiation of insulin glargine in children and adolescents with type 1 diabetes. Pediatr Diabetes, 5(2):80-6.

10. Tricco A, Ashoor H, Antony J et al. (2014): Safety, effectiveness, and cost effectiveness of long acting versus intermediate acting insulin for patients with type 1 diabetes: systematic review and network metaanalysis. BMJ., 14: 349-56.

11. Mona H, Maha A, Hend S et al. (2015): Effect of insulin glargine on glycemic control in adolescents with type 1-diabetes. Egypt Pediatr Assoc Gaz., 63(2):35-8.

12. Kordonouri O, Maguire A, Knip M et al. (2009): Other complications and associated conditions with diabetes in children and adolescents. Pediatr Diabetes, 10:204-10.

13. Chase $\mathrm{H}$, Arslanian $\mathrm{S}$, White $\mathrm{N}$ et al. (2008): Insulin glargine versus intermediate-acting insulin as the basal component of multiple daily injection regimens for adolescents with type 1 diabetes mellitus. J Pediatr., 153(4):547-53.

14. Hassan K, Rodriguez L, Johnson S et al. (2008): A randomized, controlled trial comparing twice-a-day insulin glargine mixed with rapid-acting insulin analogs versus standard neutral protamine Hagedorn (NPH) therapy in newly diagnosed type 1 diabetes. Pediatrics, 121(3): 466-72.

15. Schober E, Schoenle E, Van Dyk J et al. (2002): Glargine PSG of I. Comparative trial between insulin glargine and NPH insulin in children and adolescents with type i diabetes mellitus. J Pediatr Endocrinol Metab., 15(4):369-76.

16. Deiss D, Kordonouri O, Hartmann $R$ et al. (2007): Treatment with insulin glargine reduces asymptomatic hypoglycemia detected by continuous subcutaneous glucose monitoring in children and adolescents with type 1 diabetes. Pediatr Diabetes, 8(3):157-62.

17. Colino E, López-Capapé M, Golmayo L et al. (2005): Therapy with insulin glargine (Lantus $\left.{ }^{\circledR}\right)$ in toddlers, children and adolescents with type 1 diabetes. Diabetes Res Clin Pract., 70(1):1-7.

18. Roberts W (2004): CDC/AHA workshop on markers of inflammation and cardiovascular disease: application to clinical and public health practice: laboratory tests available to assess inflammation-performance and standardization: a background paper. Circulation, 110(25): 572-6.

19. Pérez-Segura P, De Dios O, Herrero L et al. (2009): Children with type 1 diabetes have elevated highsensitivity C-reactive protein compared with a control group. BMJ Open Diabetes Res Care, 8(1): 1424-1430. 